\title{
Private Health Insurance: Still Muddling Through
}

\section{Ian McAuley}

\begin{abstract}
A priority of the Coalition Government on taking office in 1996 was to provide incentives for people to take up private health insurance. Since then there have been several measures directed to this end, most recently a further set of incentives directed to older people.

This paper is an analysis of those measures, suggesting that whatever the purpose of the incentives may have been, they have not been cost-effective means of achieving their purpose - unless that purpose was to support private health insurance as an end in its own right. Communities choose to share some of their health care costs and to pay for others from their private resources. As a means of sharing expenses private health insurance is inferior, on all plausible policy criteria, to tax-funded single payer systems. At the same time it yields none of the benefits which privatisation normally carries, because it retains the incentive for over-use of a free service ('moral hazard') which is a characteristic of all insurance systems - private and tax-funded.

This specific failure is indicative of broader problems in health policy inadequate articulation of purpose, a focus on budgetary outlays rather than broader economic considerations, and a failure to confront basic policy questions about the boundary between use of market forces and collective mechanisms to allocate scarce health care resources.
\end{abstract}

\section{Rescuing Private Insurance - Its Decline, Rise and Decline}

\section{Trends and policies}

From 1984, when the Hawke Government reintroduced universal tax-funded hospital care (Medicare) to 1998, there was a steady decline in the proportion of the population covered by private health insurance. Over this 14 year period coverage fell from 50.0 per cent to 30.5 per cent of the population - a rate of decline of about 1.4 per cent a year. (The only other significant change in health financing which may have influenced private health insurance coverage was withdrawal of a bed-day subsidy for private hospitals in 1986.) There was speculation that at such a low level of coverage private health insurance might be approaching a 'tipping point'; in a positive feedback loop the well-off and healthy would desert private insurance, requiring the insurance funds to raise premiums, thus accelerating the exit of the well-off and healthy. 
By 1996, when the Howard Government was elected, coverage had fallen to 33 per cent. Within two months of the election the newly-appointed Health Minister, Michael Wooldridge, issued a press statement outlining the gravity of the situation (Minister for Health and Family Services, 1996):

The continuing decline in the number of Australians with private insurance is perhaps the single most serious threat to the viability of our entire health system.

The Government did not clarify why it thought this decline was so serious. Was support for private insurance a means to another end, or an end in itself? These questions on ends, important in any policy evaluation, are taken up in the next part of the paper. The incentives have certainly encouraged an increase in membership (and therefore coverage) of private health insurance, though the specific reasons this has occurred are far from clear. In fairly quick succession the Commonwealth introduced three different incentives:

(1) Commencing in July 1997, a means-tested fixed-rate subsidy for private insurance, and a tax penalty (one per cent) imposed on medium to high income earners without private insurance.

(2) Commencing in January 1999, replacement of the means-tested subsidy with a general subsidy of 30 per cent.

(3) Commencing in July 2000, 'lifetime' cover agreements, whereby premiums would rise by two per cent a year from ages 30 to 65 . This was accompanied by an intensive publicly-funded campaign - 'Run for cover'.

\section{Figure 1: Private Health Insurance Population Coverage}

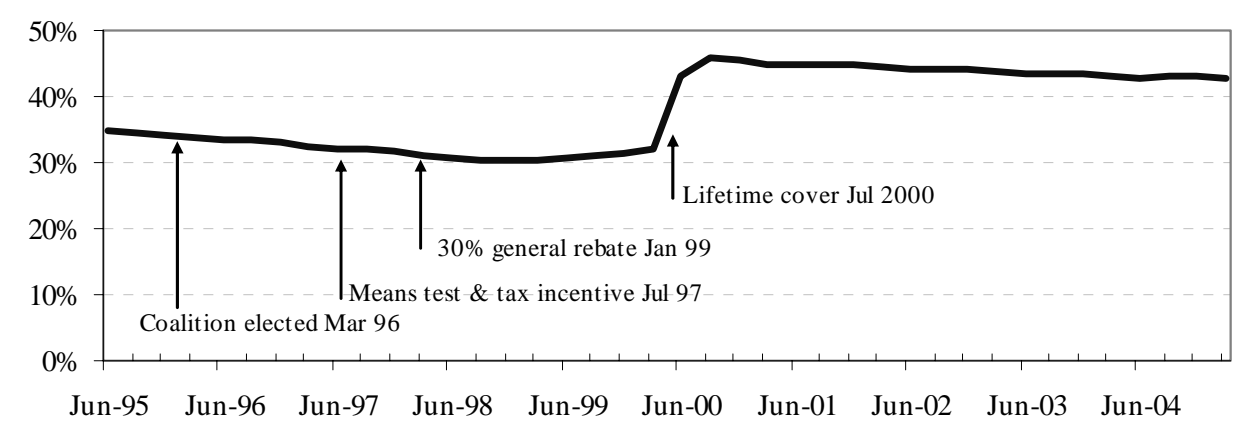

These 'lifetime' rating incentives strike a compromise between pure 'community rating', with everyone paying the same premium regardless of age, and 'risk rating', with premiums rising in line with statistical calculations of need for health care (age being a good proxy of need). Pure community rating discourages insurance by the young and healthy. Pure risk rating makes insurance unaffordable to those who need it most. (For a longer-term and more thorough description and analysis of incentives and rating systems, see Butler, 2003.) 
In addition to these major changes there have been two other measures which may have some effect in encouraging people to take up private health insurance. In 2000 the Commonwealth allowed funds to offer more generous gap insurance for the difference between the schedule fee and the fee charged for in-hospital services (removing the previous condition that these arrangements be embodied in formal contracts). And in 2005, in fulfilment of an election promise, the subsidies were raised from 30 to 35 per cent for persons aged between 65 and 69 and to 40 per cent for persons aged 70 or more.

\section{What drove the recovery}

The first two measures did not result in any immediate rise in private insurance coverage. (That leaves open the possibility that they arrested any further slide in coverage.) As a welfare measure to compensate those who held insurance they may have been well-targeted, but as a measure to encourage people to buy private insurance they had little effect. The third measure, however, was associated with a strong rise in coverage - which peaked at 46 per cent once they were in place.

The sluggish response to financial incentives suggests a low price elasticity of demand for private insurance, at least in relation to price falls. Price reductions, through direct subsidies and tax incentives, did not encourage take up of private insurance. On the other hand, income elasticity of demand for private insurance may be reasonably high. Like BMWs and Grange Hermitage, private insurance is what economists call a 'superior good'. That is, one on which spending rises strongly with income. According to an ABS survey based on 1995 data, well before there was any suggestion of subsidies for private insurance, 72 per cent of Australians in households with incomes above $\$ 70,000$ held private insurance, while only 26 per cent of those in households with incomes below \$30,000 held private insurance (ABS 1998). This unsurprising relationship between means and level of private health insurance coverage has more recently been confirmed in a study published by The Australia Institute, which found, based on a 2004 survey:

While only 24 per cent of Australians who live in households with incomes below $\$ 25,000$ per year are covered by private health insurance, the proportion rises steadily with household income; 69 per cent of those in households with incomes over $\$ 100,000$ per year have private health cover. (Denniss, 2005)

Another ABS survey, using 1998 data, found that the incentives at that time (the means-tested subsidy and the tax break) hardly rated as reasons for taking up or retaining private health insurance (see Table 1). The main reason was a perception that private insurance offered 'security, protection, peace of mind'. (Such survey responses need to be interpreted with caution; once people purchase a product they are more likely to mention a product's attributes than its price.)

It is notable that among the reasons which solicited significant responses are 'choice of doctor' and 'allows access as private patient'. It is easy for people to infer, from insurers' advertisements and from government statements, that 
treatment as a private patient is available only for those with private insurance. In fact there is no such restriction; anyone willing to pay the full cost of service can be treated as a private patient, whether they are insured or not. The reason for the success of the 'lifetime' rating incentives remains a topic of debate. John Deeble argues that if a 30 per cent subsidy failed to attract members, then it was unlikely that a two per cent annual increment would work. He suspects the combination of fear and uncertainty was a more likely reason (aligning with the 'security, protection, peace of mind' reason in the ABS survey). To quote Deeble (2003):

[T]he 'run for cover campaign' associated with 'lifetime health insurance' had a dramatic effect. Its basic message was that the government could not provide universal access to an adequate standard of hospital care through Medicare and that the only way to ensure personal coverage was to take private insurance now.

Table 1: Reasons for Holding Private Insurance

\begin{tabular}{l|c}
\hline Reason & per cent \\
\hline Security, protection, peace of mind & 72 \\
Choice of doctor & 39 \\
Allows treatment as private patient & 31 \\
Provides benefits for ancillary services/extras & 28 \\
Shorter wait/concern over hospital waiting lists & 36 \\
Always had it/parents had it/condition of job & 33 \\
Gov't incentives/to avoid extra Medicare levy & 2 \\
Other financial reasons & 6 \\
Has illness/condition likely to need treatment & 15 \\
Elderly/getting older/likely to need treatment & 15 \\
Other & 11 \\
\hline
\end{tabular}

Source: ABS Health Insurance Survey (Cat 4335.0) June 1998

By contrast, Palangkaraya and Yong (2004), using regression analysis, have concluded that the individual effect of the 'lifetime' cover campaign accounted for only around a third of the 15 per cent rise in cover. More recent work by the National Centre for Social and Economic Modelling, using data from the ABS and National Health Surveys, confirms that the 'lifetime' rating incentives were indeed responsible for the rise in coverage. The most striking feature of that research is that 'lifetime' rating was effective only for those in the highest quintile of earnings; the response from other groups was very sluggish (Walker et al, 2005). Why people in this high income group would have responded to these incentives, 
when they had failed to respond to the earlier incentives which were more financially rewarding, is an open question.

Empirical studies by James Butler found that the 'lifetime' rating measures had a strong effect, while leaving open the possibility that the rise in membership may have arisen from a combination of factors Butler (2003). Because there was a 30 June deadline before the stepped fees came into effect, people's attention may have become more focussed on all factors, including price, as the deadline approached.

From a policy perspective these arguments are important. If the objective of boosting private insurance could have been achieved by 'lifetime' rating alone, possibly with an intense publicity campaign, it is possible that financial incentives were unnecessary. Even now, with four years of ex post data, although no one would attribute all effects to one cause, the weighting of causes is still subject to dispute. And the fact that use of private insurance is sill strongly correlated with income raises questions about the distributional equity of the subsidies.

\section{More recent trends}

With the policy environment having been steady for almost five years, it is possible to observe some established trends. Private insurance coverage is again falling. Since its peak in 2000, at 8 743,000 persons, coverage has fallen by only 86,000 , but as a proportion of the growing population it has fallen from 45.7 per cent to 42.9 per cent in early 2005. The rate of fall is only about half the rate of fall that occurred over the 1984 to 1998 period, but it is showing two characteristics - seasonality and strong age selection.

\section{Figure 2: Quarterly Movements in PHI Membership}

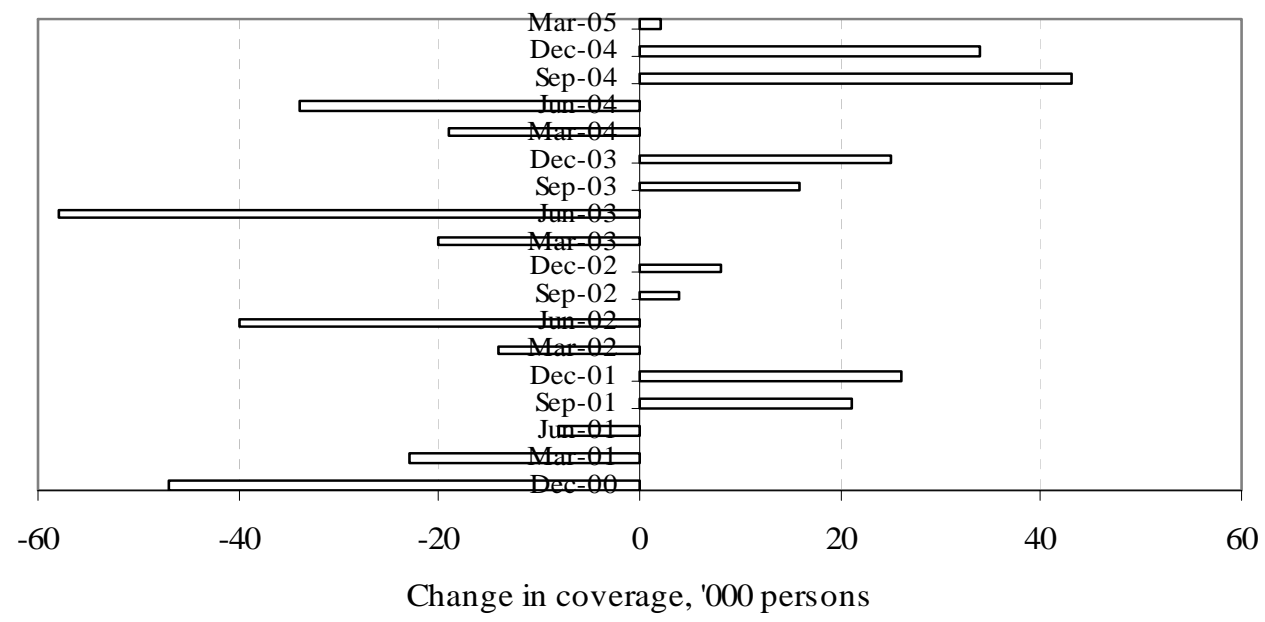

The falls tend to occur in the March and June quarters of the year, before there is a partial recovery in coverage in the subsequent quarters (see Figure 2 for a graphical representation of this seasonality). Because premium price rises occur 
in the first quarter of the year, there is a strong likelihood that this seasonality is associated with premium rises. If so, it would suggest that there is indeed some price elasticity associated with rising prices, but less so with falling prices. According to calculations by the Australian Consumers' Association (2005), premiums have risen by 70 per cent in the ten years from 1996 to 2005. This implies a real (inflation-adjusted) rise of 37 per cent over that period.

There is no economic rule dictating that people behave symmetrically with respect to price falls and rises. Empirical research in the field of behavioural economics points to many reasons why people may behave differently with respect to price rises and falls. The general explanation for such asymmetry is that when people already have a product they have some experience of its attributes and therefore its personal value; when they are considering buying a product they have to commit an act of imagination (Katzner 1999). The other trend, not obvious from the aggregate figures, is that there is a degree of age selection occurring. Younger people are deserting private insurance, while older people, who have more need for health care, are retaining it or taking it up. The incentives built into ‘lifetime' rating are not strong enough to hold younger members.

Table 2: Change in PHI Coverage by Age Sept 2000 — March 2005

\begin{tabular}{l|r}
\hline Age group & Change \\
\hline $0-9$ & $-121,000$ \\
$10-19$ & $-69,000$ \\
$20-29$ & 42,000 \\
$30-54$ & $-334,000$ \\
$55-64$ & 230,000 \\
$65+$ & 169,000 \\
All & $-83,000$ \\
\hline
\end{tabular}

Source: PHIAC Reports (rounded)

This feedback process, which leaves insurers with high risk and more costly members (necessitating premium rises and more desertion by low risk members), is known as 'adverse selection'. In his study James Butler (2003) found that, in spite of the 'lifetime' rating incentives, adverse selection was occurring. Evidence from two years of additional data supports Butler's findings - the loss of membership having been most pronounced in the 30 to 54 age group, and the gain most pronounced in the older age groups. As we shall see, 55 is close to the age where the 'average' consumer can start to draw more from funds than they contribute.

By examining PHIAC data on benefits paid by age, and using the price of a typical product (Medibank 'smart choice' hospital) as a basis to calculate the cost of taking up private health insurance at different ages, it is possible to find a first order estimate of the age at which the average person will start to break even. The 
result of this calculation, based on benefit data for the year to March 2005 and price data in May 2005, is shown in Figure 3.

Figure 3: Private Health Insurance Break-Even by Age

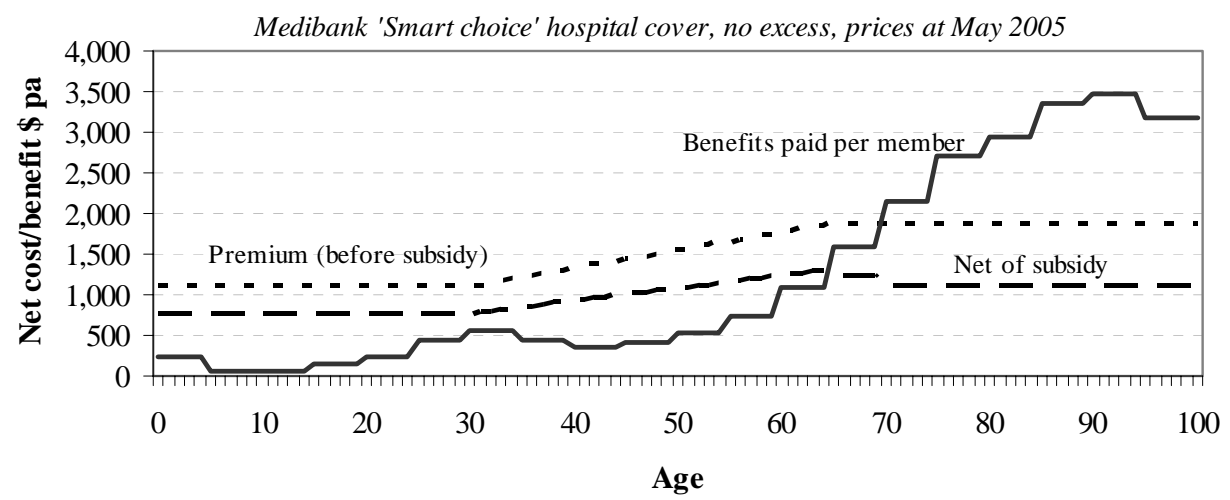

This shows the compromise built into 'lifetime' rating, in that the lifetime rating prices rise less steeply than likely use. It also shows that a risk-neutral, rational, 'average' consumer would be wise to defer taking up private insurance until he or she is around 60. (The figures are a little different for men and women.) This does not take into account the tax benefits for higher income earners, covered a little further on. Perhaps what we are observing is consumer behaviour which, over time, aligns with this 'rational' model. Behavioural economists know that consumers' immediate market decisions are far from what would emerge from calculated, rational considerations of statistical expected values. They are influenced by various biases, often towards risk aversion. But, over time, consumers may come closer to 'rational' decisions.

Deferring the age to take up private insurance makes sense, particularly now that the Commonwealth provides extra incentives past the age of 65 which partly offset the incentives built into 'lifetime' rating. Why the Commonwealth should have introduced a measure which partially offsets its other incentives is puzzling, but, fortunately for public revenue and the funds, as at March 2005 these incentives seem to have had only a slight effect. Over the December 2004 and March 2005 quarters coverage of people aged 65 or older rose by 13,000 per quarter, compared with a longer term trend of 9,000 per quarter, suggesting they have attracted only around 8,000 more members.

What may be providing a backstop to private insurance, slowing down the unravelling caused by adverse selection, is the one per cent taxation incentive applying to high income earners. The 'Medicare levy surcharge' income threshold is $\$ 50,000$ for singles and $\$ 100,000$ for families, with some minor allowances for children. Notably, the $\$ 50,000$ cut-off has not been indexed since it was introduced in 1997, when it would have been around 80 per cent of average weekly adult earnings. Now it is at about 100 per cent of average weekly adult earnings. 
The lowest price health insurance products available are around $\$ 400$ a year once the subsidy is taken into account (for example, Medibank 'First Choice Saver', a policy with exclusions and maximum excess). That means a person with an income of $\$ 50,000$ has a net $\$ 100$ incentive to take up the product (one per cent of $\$ 50,000-\$ 400$ ). A person with an income of $\$ 70,000$ faces a $\$ 300$ incentive. Even in the days of high tariff and quota assistance for manufacturing there was never a case of subsidies so high that people were actually paid to take a product.

\section{Successful So Far, but to What End?}

The measures have probably rescued the private health insurance industry, but what was their ultimate policy purpose? There is no clear, single objective outlined in the Government's policy statements. On introducing the initial incentives in 1996, the Minister's Second Reading Speech referred to the need to take pressure off public hospitals, to recognition of the private sector, to the preservation of choice, and above all to a need 'to arrest the catastrophic decline in the level of participation in private health insurance'. (House Hansard 13 December 1996)

The Minister's second reading speech on introducing the 30 per cent general subsidy claimed it would 'help the private sector, take pressure off the public hospitals system and help restore much needed balance to our health system' (without any indication of what is meant by 'balance'). The Minister went on to refer to 'upholding people's choice', 'the virtual haemorrhaging of the private sector', 'pressure on the public purse' and supporting 'the viability of the private health sector'. (House Hansard 12 November 1998)

These are not sharp, directed statements of policy. They (and other statements by industry advocates) imply that the Government's measures may be directed to some or all of the following possible purposes:

(1) To support private hospitals.

(2) To ease pressure on public hospitals.

(3) To provide choice to consumers.

(4) To save budgetary outlays.

(5) To achieve equity, compensating those with private health insurance.

(6) To direct public expenditure to those most in need.

(7) To support private insurance as an end in itself.

\section{Support for private hospitals}

There are sound reasons to prevent a collapse of private hospitals; they are valuable assets. If all activity were to move to the public sector there would be a serious misallocation of resources, with some overstretched while others would be unused. While staff may move, assets such as operating theatres and other fixed capital items in private hospitals would remain idle. 
If such support was the purpose it is questionable why such an indirect means has been used. Table 3 shows that of the $\$ 6.8$ billion of health care expenditure passing through the funds, only $\$ 3.6$ billion went to private hospitals. Once administrative costs are taken into account, less than half of the funds outlaid by private insurers make their way into providing hospital services.

Table 3: Expenditure Through Private Insurance Funds 2002-03

\begin{tabular}{l|rrr}
\hline \$million & Gross & Rebates & Net \\
\hline Public hospitals & 411 & 125 & 286 \\
Private hospitals & 3,648 & 1,112 & 2,536 \\
Ambulance & 132 & 40 & 92 \\
Medical services & 699 & 213 & 486 \\
Other health professionals & 475 & 145 & 330 \\
Pharmaceuticals & 75 & 23 & 52 \\
Aids \& appliances & 341 & 104 & 237 \\
Dental services & 978 & 298 & 680 \\
Total services & 6,759 & 2,060 & 4,699 \\
Administration & 828 & 252 & 576 \\
Total expenditure & 7,587 & 2,312 & 5,275 \\
\hline
\end{tabular}

Source: AIHW Health Expenditure in Australia 2002-03, Table A4.

This $\$ 3.6$ billion which made its way into public hospitals was supported by $\$ 2.3$ billion of public expenditure - a figure which does not include the cost of revenue foregone ('tax expenditure' or 'rebates') to fund the tax incentives for private insurance. Had the funding of $\$ 2.3$ billion been directed wholly to private hospitals, without passing through private insurance as a financial intermediary, they could have received an extra $\$ 1.2$ billion on top of their $\$ 1.1$ billion. The level of subsidy could have been almost 50 per cent ( $\$ 2.3$ billion out of total expenditure of $\$ 3.6$ billion plus $\$ 1.2$ billion).

Vaithianathan (2002) made a strong case for reallocating the insurance subsidies to direct funding of private hospitals. A bed-day subsidy, as used in the past, is a possible mechanism for direct funding. A more thorough reform could use the same funding formula for public and private hospitals, with payments on a diagnostic related group basis. There are some practical transitional arrangements to be considered, including mechanisms for capital funding for private hospitals (see McAuley, 2004 for more detail). In such arrangements private insurers could still operate in the market, but, because funding would bypass insurers, they would not be subsidised for administration, ancillary or medical gap payments.

\section{Easing pressure on public hospitals}

This is a complementary objective to supporting private hospitals, the theory being that if more activity is carried out in private hospitals there will be an easing of pressure in public hospitals. There is a fundamental flaw in such logic, however. 
In the short to medium run crucial health care resources, particularly nursing and specialist staff, are in constrained or 'inelastic' supply. Medical specialists are mobile between private and public hospitals. When more money goes into one sector, so too will resources flow into that sector. That was the warning independent academics made before the Senate committees considering these bills when they were first presented. At that stage arguments rested on the basic deductive logic of economic theory; when resources in a system are constrained more money, private or public, does no more than to bid up the price of those resources. In terms of waiting lists all that is likely is a re-shuffling of the queues.

Over the following years evidence has mounted confirming these predictions. Increased private sector throughput is reducing the capacity of the public sector, while waiting times are growing. (For an early analysis see Duckett and Jackson, 2000. As evidence mounted more studies emerged, for example, McAuley, 2004; and more comprehensively Duckett, 2005.) These and other studies indicate that there is more than a simple transfer of activity from one sector to the other. In many cases private patients in private hospitals are receiving more services for the same condition than they would have had they presented as public patients in public hospitals. This implies some level of resource misallocation (based on the normative principle that scarce health care resources should be allocated to achieving the most effective health outcomes). The differences in treatments suggest that there is either some wasteful over-servicing in the private sector or some harmful under-servicing in the public sector. If 'balance' is defined in terms of equating health outcomes at the margin in both the private and public sectors, it is not aided by increasing funding for one sector at the expense of the other.

Furthermore, those who take low-cost policies with high deductibles and exclusions (such as the $\$ 400$ policy illustrated earlier) have no incentive to use a private hospital where they will have to make significant co-payments, when they can gain free access to a public hospital. When people behave in this way they add to the revenue of the funds without taking pressure off public hospitals.

\section{Providing choice}

At first sight, consumers have more choice. The incentives have made private health insurance available to many more people, including those with comparatively modest means. It is important, however, to distinguish choice of insurer with choice of service provider. There is not a great deal of variety in the offerings of the private insurers; indeed it is hard to see how there could be much variety in such a highly regulated industry which is offering no more than simple financial services. Even when it comes to choice of service providers, in health care effective consumer choice is constrained in two further ways. Consumers may choose a particular GP as a 'gateway' to the hospital system, but the GP will have a strong influence on consumers' choice of hospital specialists. Health care involves strong information asymmetries; the consumer is much less knowledgeable than the provider. Although more consumer information is becoming available on line, there are learning costs involved, and it is hard to 
obtain any more than anecdotal information about the competence of a particular specialist. Unlike many consumer goods with repeat purchases (known as 'experience goods'), in health care opportunities for consumer learning are limited; consumers certainly hope that tumours and fractures are not experienced too frequently. And if more health funds enter into preferred provider arrangements with private hospitals, choice is further constrained.

Perhaps the greatest constraint on choice comes when people with means no longer consider public hospitals to be suited to their needs. Shared systems, such as public schools and public hospitals, can be subject to the phenomenon of 'tipping' - a term coined by Thomas Schelling (1978) in his studies of social systems. Even if the vast majority may prefer a shared system, once a sub-critical mass of people are removed from a shared system into exclusive areas of service provision, others feel compelled to follow. The choice of the minority constrains the choice of others. Choice is constrained if it is between a run-down public system and a private system funded by costly private insurance companies. Freedom to opt out is at the expense of reduced access for those who cannot afford to opt out, and at the expense of those who are forced to opt out when they would have preferred a high quality shared system.

\section{Saving public expenditure}

Saving public expenditure would seem to be an uncontentious public policy objective. In official documents concerned with health care such as Budget papers and the Intergenerational Report the focus is purely on public expenditure. A little consideration, however, leads one to question why there is any virtue in making a saving on public expenditure if the result is an even higher level of expenditure being required in the private sector to achieve the same outcome.

In terms of administrative costs alone, private health insurance incurs significantly higher bureaucratic costs than the public revenue system. From Table 3 we can see that private insurers in 2002-03 incurred \$828 million in administrative costs in their turnover of $\$ 7,587$ million, giving an expense proportion of 10.9 per cent. By contrast, in 2001-02 (the latest year for which such data is available), Medicare with a turnover of $\$ 8,023$ million, incurred management expenses of \$291 million, or 3.6 per cent. To this must be added the costs incurred in the Australian Taxation Office of collecting tax - about another 1.2 per cent. This is an upper estimate of collection costs, for it is based on the average rather than the marginal cost of tax collection. Therefore the total cost of collection and distribution of Medicare funds is at most around 4.8 per cent - 6.1 per cent lower than the administrative cost of private insurance.

This is not to suggest that there is any mismanagement in private health insurance; indeed, at 10.9 per cent their administrative cost ratio is much lower than for many other classes of insurance. But, unlike the Tax Office and the Health Insurance Commission, private insurers must advertise for business, they have to maintain customer offices in competition with other funds, and they lack the legislative authority of taxation to collect revenue. 
The stronger economic case against private health insurance lies in the capacity of a single national insurer to exercise purchasing power in the market. All insurance, public or public, carries an incentive for over-use and for a degree of indifference about the price of the service, because the cost to the user is free or heavily subsidised at the time of delivery. (There may even be a sense of entitlement based on the consumer's prior investment in an insurance premium.) Insurers refer to this phenomenon as 'moral hazard'.

Another aspect of moral hazard comes from the supply side when health care providers believe that the fund holders are able to pass on their costs to their members. This is particularly likely with private insurance; while governments with a single pool of funding can use their concentrated purchasing power to exert cost control, private insurers can be played off against one another. Even if an insurance firm desires to control service providers' charges, it has little ability to do so; if it fails to meet the demands of service providers its rivals will meet those demands, attracting those who seek comprehensive 'no gaps' cover. In health care there are many instances of concentrated provider power, including pharmaceutical firms with patent-protected property rights, chains of private hospitals, and medical specialists ready to respond to the opportunity presented by their being in short supply. Private insurance provides a permissive environment for those who seek to draw profit from the health care system.

That is why countries which have relied on private insurance to fund health care have paid a high price for that decision. The more a nation relies on private insurance to fund health care, the higher are its total health care costs, as Figure 4 illustrates for OECD countries. These are all reasonably prosperous countries, with broadly similar health care outcomes. They include countries with aged populations, such as Italy and the Scandinavian countries, which have been able to keep health care costs under control by keeping private insurance confined to the periphery of their systems. And the outlier at the extreme end is the USA, where private health insurance accounts for 36 per cent of funding and health care expenditure is around 14 per cent of GDP.

The paradox of the USA is that with health care costs out of control, because of the moral hazard created by a fragmented private health insurance system, the Government has lost the capacity to control costs in its own programs - Medicare for the aged and Medicaid for the 'indigent' - both of which are parsimonious in their coverage. By 2002 these limited programs cost the Government 6.2 per cent of GDP which is above the OECD average of 6.1 per cent and about the same as the public outlays in those European countries with universal government-funded health insurance schemes. The IMF has warned the USA about runaway budgetary outlays on health care, mainly through the Medicare program, citing political stubbornness as an impediment to meaningful reforms (Mühleisen and Towe, 2004). Similarly the OECD has issued a warning to Australia:

Private funds have not effectively engaged in cost controls. They seem to have limited tools and few incentives to promote cost-efficient care, and there are margins for some funds to improve administrative 
efficiency, thereby reducing administrative costs. PHI appears to have led to an overall increase in health utilisation in Australia as there are limited constraints on expenditure growth. Insurers are not exposed to the risk of managing the entire continuum of care. The Medicare subsidy to private in hospital medical treatment has also reduced funds' accountability for the real cost of private care. Policies to reduce medical gaps have led to some price increase and may have enhanced supply-side moral hazard incentives. (Colombo and Tapay, 2003)

\section{Figure 4: Private Health Insurance and Total Health Expenditure, OECD Countries}

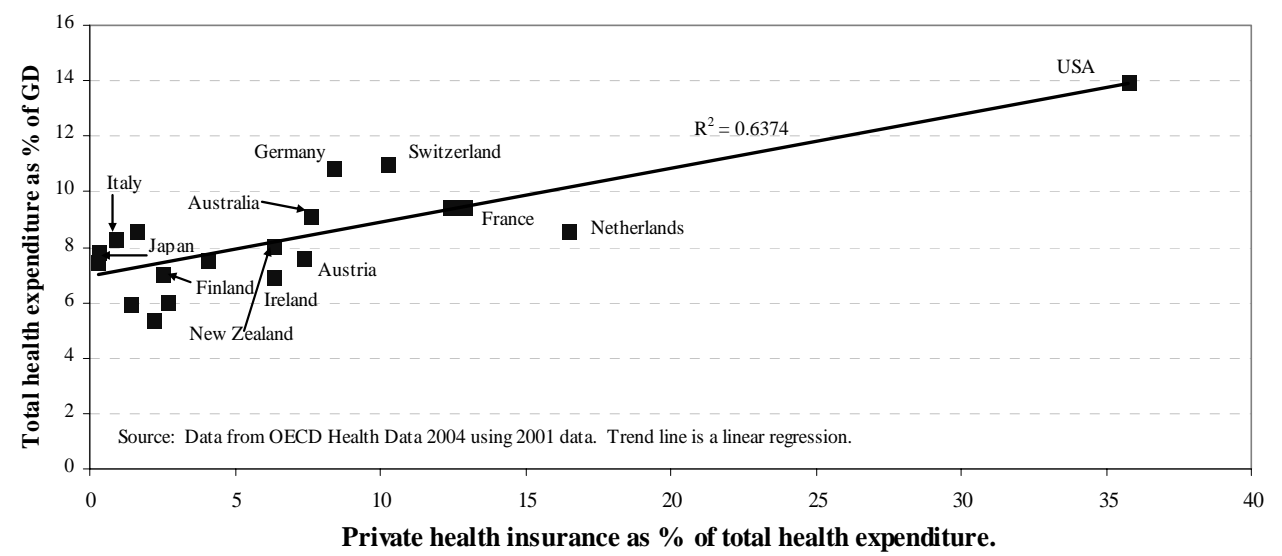

In Australia, there is no evidence that the private health insurance subsidies have resulted in any saving in Commonwealth or state hospital budgets. While total hospital spending has risen at an annual rate of 6.6 per cent since 1995-96, Commonwealth spending has risen at a rate of 10.3 per cent. Even with the subsidies, private health insurance has done no more than to sustain its share of the financing load. (See Table 4.)

The budgetary case for subsidising private insurance is weak. Even if such support were to reduce the call on public funds (an assumption not supported by evidence), there is no intrinsic virtue in shifting an activity to the private sector, particularly if the result in such a shift is more total expenditure (the sum of public and private expenditure) without any improvement in technical or allocative efficiency. Private health insurance is what Naomi Caiden (1987) refers to as a 'privatised tax'. Privatised taxes are usually expensive to collect and they do not have the benefits of transparency, cost control and fairness of official taxes. In the case of health care, the taxation system has a rating system which distributes the burden between the poor and the well-off with a degree of progressive redistribution. By contrast, the achievement of even partial community rating in private health insurance is difficult. 
Table 4. Sources of Hospital Funding — 1995-96 to 2002-03 (\$million)

\begin{tabular}{|c|c|c|c|c|c|c|c|c|c|}
\hline & \multicolumn{3}{|c|}{ Commonwealth } & \multirow{2}{*}{$\begin{array}{c}\text { State } \\
\text { Gov-mts }\end{array}$} & \multirow{2}{*}{$\begin{array}{c}\text { Total } \\
\text { Gov-mts }\end{array}$} & \multirow{2}{*}{$\begin{array}{l}\text { Funds } \\
\text { (incl } \\
\text { rebates) }\end{array}$} & \multirow[t]{2}{*}{ Consumer } & \multirow[t]{2}{*}{ Other } & \multirow[t]{2}{*}{ Total } \\
\hline & Direct & $\begin{array}{l}\text { PHI } \\
\text { rebates }\end{array}$ & Total & & & & & & \\
\hline $95-96$ & 5580 & & 5580 & 5274 & 10854 & 2611 & 306 & 1012 & 14783 \\
\hline $96-97$ & 5778 & & 5778 & 5869 & 11647 & 2797 & 402 & 1009 & 15855 \\
\hline $97-98$ & 6247 & 147 & 6394 & 6469 & 12863 & 2748 & 428 & 1095 & 16987 \\
\hline $98-99$ & 7101 & 556 & 7657 & 6721 & 14378 & 2813 & 664 & 938 & 18237 \\
\hline $99-00$ & 7497 & 881 & 8378 & 6847 & 15225 & 2900 & 661 & 1225 & 19130 \\
\hline 00-01 & 8069 & 1087 & 9156 & 7100 & 16256 & 3312 & 693 & 1203 & 20377 \\
\hline 01-02 & 8623 & 1118 & 9741 & 7323 & 17064 & 3782 & 719 & 1327 & 21774 \\
\hline 02-03 & 9315 & 1237 & 10552 & 7902 & 18454 & 4059 & 738 & 1358 & 23372 \\
\hline $\begin{array}{l}\text { Annual } \\
\text { growth }\end{array}$ & $7.9 \%$ & & $10.3 \%$ & $5.2 \%$ & $7.9 \%$ & $6.4 \%$ & $13.3 \%$ & $4.8 \%$ & $6.6 \%$ \\
\hline
\end{tabular}

Source: Financial data from AIHW Health Expenditure Bulletin, various issues. PHI coverage from PHIAC 'C' tables. Growth obtained by logarithmic curve fit.

This is not to establish a general case against privatisation. In many cases privatisation and break-up of state monopolies bring benefits of competition in the form of lower prices, innovation and expanded choice. Markets work more often than they fail. But those conditions do not hold for private health insurance. Insurance is a means of buying out of the discipline of market forces; it suppresses the price signals which are vital to the operation of markets. In the absence of the discipline of the invisible hand of market forces, a single national insurer offers the best opportunity to control prices.

Nor is it to establish a case for universal, free, tax-funded health care services. There is an arguable case, in a prosperous society, for people to pay more from their own resources for health care, providing a stronger role for market forces without the distortion of insurance. The argument is that for that portion of health care funding people choose to pool, a single national insurer is the most efficient mechanism.

Equity for the insured

When health insurance coverage rose from 30 per cent to 46 per cent, two thirds of the subsidy benefits flowed to people who already held insurance. This has been used as a point of criticism of the incentives, in that they have been an expensive way to achieve a change in behaviour. (See, for example Deeble, 2003 and many other analysts). It could also be seen, however, in terms of equity for those who have taken responsibility for their own health care expenditure. 
This argument would be more credible if the taxation incentives were not structured in such a way that over-compensates the well-off. It also ignores the equity considerations of the self-insured - those people who pay for private hospital funding from their own resources.

Figure 5 shows that since there have been incentives for private insurance the proportion of people who use private hospitals without being dependent on private insurance has fallen sharply. Correlation does not establish causation of course, and more research would be necessary to establish the reasons for this fall off, but the incentives do not provide equity for the most self-reliant who save for their own health care. The incentives de facto penalise private savings (when there is a national problem of low household saving). While it is a defensible ideology which sees virtue in people taking more responsibility for their own needs without depending on collective arrangements, it is a strange ideology which suggests that dependence on an insurance corporation is more virtuous than dependence on a government agency.

\section{Figure 5: Private Hospitals Separations Without Private Insurance}

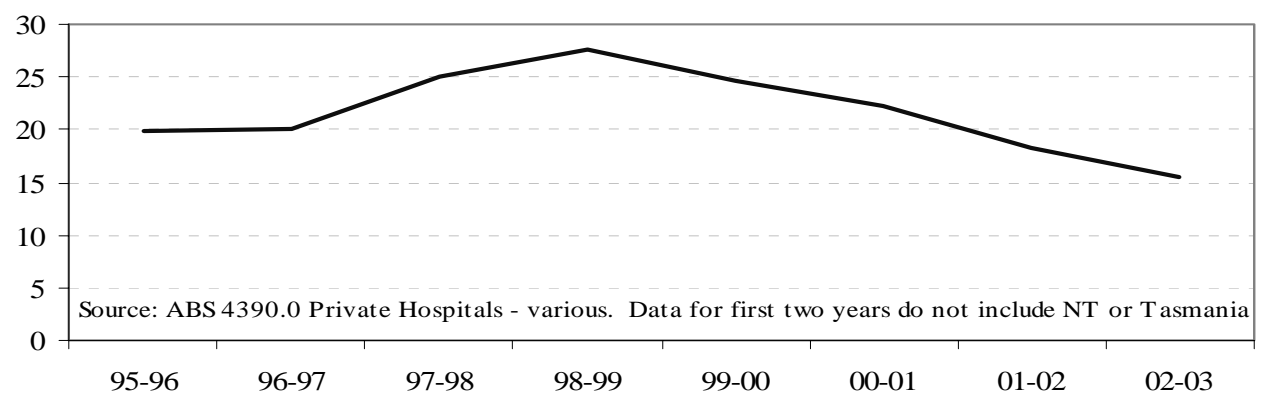

As mentioned earlier, there is possibly a default assumption held by the community and its elected representatives, that private hospitalisation will inevitably be funded by private insurance. The funds' advertisements do nothing to dispel this assumption. Such an assumption ignores the fact that many households have high levels of liquid or near-liquid wealth. In 2002 half of all households had share, and bank-account, assets in excess of $\$ 27,000$. Such wealth tends to rise with age; the mean figure for households with a reference person in the 65 to 74 age bracket is $\$ 95,000$ (Headey et al, 2004). If a government wishes to encourage self-reliance, a starting point would be to give the same or greater incentives to those who pay for private hospitals from their own resources as they do to those who depend on private insurance.

Directing public expenditure to those most in need

The Commonwealth has never formally stated that it intends to develop a two tier system of health financing, with public services set aside for the poor, although during the 2004 election campaign Deputy Prime Minister John Anderson did 
suggest that a two-tier system might be acceptable to the electorate. Gwendolyn Gray (2004:90-91) has collated a number of statements suggesting that within the Ministry there is a degree of hostility towards Medicare's universality.

Not everyone seeks information on public policy from ministerial statements or second reading speeches; public understanding of a program's objectives is not necessarily well-informed. There is indeed a notion that Medicare is primarily a welfare program. For example, a Sydney Morning Herald editorial (1 May 1998) asserted that Medicare was 'designed as a publicly funded safety net for the disadvantaged minority.'

In a 2005 report on national competition policy, the Productivity Commission (2005:330) suggested 'without endorsing any particular approach', that a possible option to health care reform would be 'allowing, or obliging, those people who can afford adequate private health insurance to opt out of the public system'.

It is important to distinguish the effects of a program from its intention. Medicare does have welfare benefits for the most disadvantaged because the poor and the old are likely to be the heaviest users of health care. But it is also a universal program.

Table 5: Publicly-Funded Health Benefits, \$ per Week per Head, by Household Income Quintile

\begin{tabular}{l|ccccc}
\hline & $\begin{array}{c}\text { Lowest } \\
\mathbf{2 0 \%}\end{array}$ & $\begin{array}{c}\text { Second } \\
\text { quintile }\end{array}$ & $\begin{array}{c}\text { Third } \\
\text { quintile }\end{array}$ & $\begin{array}{c}\text { Fourth } \\
\text { quintile }\end{array}$ & $\begin{array}{c}\text { Highest } \\
\mathbf{2 0 \%}\end{array}$ \\
\hline Hospital care & 29 & 23 & 13 & 11 & 11 \\
Medical clinics & 13 & 12 & 10 & 10 & 10 \\
Pharmaceuticals & 7 & 6 & 3 & 2 & 1 \\
Other health benefits & 3 & 3 & 3 & 3 & 3 \\
Total health benefits & 53 & 44 & 29 & 26 & 25 \\
Private income & 10 & 90 & 227 & 342 & 592 \\
$\begin{array}{l}\text { Ratio health benefits to } \\
\text { private income }\end{array}$ & $534 \%$ & $49 \%$ & $13 \%$ & $7 \%$ & $4 \%$ \\
\hline
\end{tabular}

Source: ABS Household Expenditure Survey 1998-99, Cat 6537.0 — household data divided by household size.

Table 5 illustrates transfers in publicly-funded health programs and shows that the absolute financial benefit to people in the highest income households is only half that enjoyed by people in the lowest income households. (The data are from 1988, before private health insurance levels had risen.) Universal, taxfunded health insurance is a low cost social contract.

Saving private insurance

This brings us to the last plausible policy objective - that rescuing private insurance was an end in itself. By the time the Coalition came to office the private 
insurance funds were struggling. Not only was their membership falling, but also their returns on invested reserves were falling. Insurance funds generally, with reserves conservatively invested in interest-bearing deposits, were under stress as interest rates fell. The funds' investment income fell heavily between 2001 and 2002 as they drew down reserves and as the earnings on those reserves fell - a development which the funds and the Government probably anticipated when they were drawing up the 'lifetime' rating incentives.

Governments have no brief to protect particular industries. The days of paternalistic tariff protection are well over. And if the subsidies were an industryprotection measure, it is unlikely that assistance for a financial intermediary should have come from the health budget. More appropriately the subsidies and tax expenditures should have appeared in the Treasury or Industry budget.

The possible explanation is that the policy was not carefully thought through, but that it was a poorly-considered response to what was seen as an emerging problem. Policy makers and advocates generally propose solutions within existing institutional arrangements. They know their way around the existing system, and assume basic institutional arrangements to be immutable. To use Charles Lindblom's famous term, they are content to 'muddle through', with incremental change in response to problems, rather than basic change. (Lindblom, 1959)

Lindblom's work is often taken as a defence of such an approach to policy development, but in his work he makes it clear that muddling through is flawed. He states: '... the method is without a built-in safeguard for all relevant values, and it also may lead the decision-maker to overlook excellent policies for no other reason than that they are not suggested by the chain of successive policy steps leading up to the present.' He also warns about ignoring possible consequences of policies, and about the risk of confusing means and ends.

The Government did send a reference to the Industry Commission (1997), but it was a narrow reference, essentially asking the Commission to evaluate means to support private health insurance. The Commission included in its report a recommendation that there be a broad public inquiry into Australia's health system. Such an inquiry would consider many issues, including funding, federal/state responsibilities, possible integration of services, and the balance between direct payments and insurance mechanisms (public and private).

The Government did not act on this recommendation, and in three subsequent election campaigns both major parties have tended to focus on specific issues such as subsidies for private health insurance, co-payments for pharmaceuticals, programs for the aged (Medicare Gold), bulk-billing - rather than any systemwide policy. In contrast with this cautious, incremental political approach, speakers and other delegates at the 2003 Health Summit, stressed the need for a broader policy perspective on health care. They pointed out technical and allocative inefficiencies resulting from a lack of integration of programs, from conflicting and perverse incentives on users and service providers, and from fiscal incentives on governments for cost and responsibility shifting. 


\section{Conclusion}

It is reasonable to conclude that the Commonwealth's initiatives have failed on the basis of all plausible policy objectives but for one. That one success has been the rescue, for now, of the private health insurance funds. Their coverage, at 43 per cent, is restored to where it was in 1991, and is falling more slowly.

Evidence strongly suggests that even this modest outcome - the rescue of a financial intermediary - could have been achieved at lower cost. The 'lifetime' incentives alone, or a similar set of measures with more modest subsidies, may have achieved the same result without spending more than two billion dollars a year on subsidies.

One cannot know the inner workings of public policy. Was the Government's aim to rescue private insurance as an industry protection measure? Or was it a textbook case of the limited policy thinking described by Lindblom confusion of means and ends and a preference for using existing policy instruments rather than a consideration of more basic approaches?

Is the explanation more mundane? An ideology suggesting that 'private' is better than 'public', even if the economic and fiscal costs of a transfer from the public to the private sector are high? A failure to distinguish private health care funding from private health care provision? A failure to distinguish between funds and real resources; that is, a belief that spending money on a problem will solve it, even if the real resources are unavailable? Or a failure to understand the true nature of insurance - that any form of insurance, private or public, carries an incentive for over-use and price inflation?

By specifying a number of purposes for the initiatives the Commonwealth has covered itself politically, but such an approach comes at the cost of clarity. There are two fundamental questions about health financing which remain unanswered; in fact they are not even being asked.

The first is what part of our health care costs should we share through insurance and what should we pay for from our own pockets? Evidence and basic economic logic suggest that a single national insurer is the most efficient and equitable way to pool our funds, but the question remains open as to the extent to which direct payments, without any insurance support, should be used to harness some of the discipline of market forces. Universal health care systems entered the policy debate around sixty years ago, in the postwar era. Since then we have become much wealthier and it is realistic to assume that we have more capacity to take on more of our own health care costs without insurance. There is no necessary conflict between universal public insurance and use of market forces for part of our costs.

The other is where to draw the boundary between those services which should be free or subsidised and those which should be left to a comparatively unsupported market. At present there is no logical consistency in our health care programs. Some are free (bulk billed services, public hospitals); some have capped co-payments (prescription pharmaceuticals); some have open-ended copayments (most privately insured ancillary services); some have proportional co- 
payments (most medical services once a safety net is reached); some have no support (uninsured dental, physiotherapy and similar services).

These are the basic questions which have so far eluded both the Government and Opposition, but they are the questions appropriate for an inquiry such as that recommended by the Industry Commission in 1997.

This paper concludes with an articulation of those questions, rather than an attempt to answer them. Their answer requires extensive community consultation, a process which would involve putting forward options, educating the public about consequences of possible choices, and ultimately, developing a well-integrated health care system underpinned in a set of clearly expressed values.

\section{References}

Australian Bureau of Statistics (1998), Private Health Insurance 1995 (Cat 4334.0).

Australian Bureau of Statistics (1999), Health Insurance Survey 1998 (Cat 4335.0).

Australian Consumers’ Association (2005), 'Health insurance premiums rise again’ Choice May 2005.

Butler, J. (2003), 'Adverse Selection, Genetic Testing and Life Insurance — Lessons from Health Insurance in Australia’, Agenda 10(1):73-89.

Colombo, F. and N. Tapay (2003), 'Private Health Insurance in Australia: A Case Study', Health Working Papers No. 8, OECD, Paris.

Deeble, J. (2003) 'The Private Health Insurance Rebate - Report to State and Territory Health Ministers', National Centre for Epidemiology and Population Health, ANU, January.

Caiden, N. (1987), 'Patterns of Budgeting', pp. 53-60 in A. Schick (ed.), Perspectives in Budgeting, American Society of Public Administration.

Industry Commission (1997), Private Health Insurance Report 57, AGPS, Canberra.

Denniss, R. (2005), 'Who Benefits from Private Health Insurance in Australia?', The Australia Institute, March, http://www.tai.org.au/Publications_Files/Papers\&Sub_Files/ Private\%20health\%20insurance\%20by\%20income.pdf.

Duckett, S. and T. Jackson (2001), 'The New Health Insurance Rebate: An Inefficient Way of Assisting Public Hospitals’ Medical Journal of Australia 172:439-42.

Duckett, S. (2005), 'Private Care and Public Waiting', Australian Health Review 29(1):8793.

Gray, G. (2004), The Politics of Medicare: Who Gets What, When and How, UNSW Press, Kensington, NSW.

Headey, B., G. Marks and M. Wooden (2004), 'The Structure and Distribution of Household Wealth in Australia', Working Paper No. 12/2004, Melbourne Institute of Applied Economic and Social Research. 
Katzner, D. (1999), 'Hysteresis and the Modeling of Economic Phenomena' Review of Political Economy 11(2):171-181.

Lindblom, C. (1959), 'The Science of Muddling Through', Public Administration Review 19:79-88.

McAuley, I. (2004), 'Stress on Public Hospitals: Why Private Insurance Has Made it Worse’, Australian Healthcare Association, http://www.aha.asn.au/publications/.

Mühleisen, M. and C. Towe (2004), 'U.S. Fiscal Policies and Priorities for Long-Run Sustainability’, IMF, http://www.imf.org/external/Pubs/NFT/Op/227/.

Productivity Commission (2005), Review of National Competition Policy Reforms Report No 33, Canberra.

Palangkaraya, A. and J. Yong (2004) 'How Effective is "Lifetime Health Cover" in Raising Private Health Insurance Coverage in Australia? An Assessment Using Regression Discontinuity', Working Paper No. 33/2004, Melbourne Institute of Applied Economic and Social Research.

Minister for Health and Family Services (1996), Media Release, 24 May.

Schelling, T. (1978), Micromotives and Macrobehavior, W W Norton , New York.

Vaithianathan, R. (2002), 'Will Subsidising Private Health Insurance Help the Public Health System?’, The Economic Record 78(3):277-283.

Walker, A., R. Percival, L. Thurecht and J. Pearce (2005), 'Distributional Impact of Recent Changes in Private Health Insurance Policies’ Australian Health Review 29(2):167177.

All data, except where otherwise indicated, is drawn from Private Health Insurance Administration Council tables, various years. The author would like to thank two anonymous referees for their comments 